\title{
Growth, ruminal measurements, and health characteristics of Holstein bull calves fed an Aspergillus oryzae fermentation extract
}

\author{
T. T. Yohe, K. M. O'Diam, and K. M. Daniels ${ }^{1,2}$ \\ Department of Animal Sciences, Ohio Agricultural Research and Development Center, The Ohio State University, Wooster 44691
}

\begin{abstract}
A fermentation extract of the fungus Aspergillus ory$z a e$ can be used as a prebiotic. The objective was to determine if dietary inclusion of a fermentation extract of A. oryzae as well as calf age would alter growth, health, performance parameters, and the growth and development of the rumen in Holstein calves from birth thru 1 wk postweaning; it was hypothesized that it would. Purchased bull calves $(\mathrm{n}=52)$ that originated from 1 of 13 farms were used in this experiment. All calves had serum IgG greater than $10 \mathrm{mg} / \mathrm{mL}$. Calves were randomly assigned to a slaughter age, $4(\mathrm{n}=16)$ or 8 wk $(\mathrm{n}=36)$, and treatment, control $(\mathrm{n}=27)$ or fermentation extract of $A$. oryzae (AMF; $\mathrm{n}=25)$. Calves were housed and fed individually; no bedding was used and no forage was fed. Calves assigned to AMF were fed $2 \mathrm{~g}$ of AMF daily. Liquid AMF was delivered in milk replacer for the first 4 wk of the study; solid AMF was top-dressed on texturized starter thereafter. Calves were fed nonmedicated milk replacer twice daily $(22.0 \%$ crude protein, $20.0 \%$ fat, dry matter basis; $680 \mathrm{~g} / \mathrm{d}$ ) and were weaned upon consumption of $0.91 \mathrm{~kg}$ of starter (20\% crude protein, $2.0 \%$ fat; medicated with decoquinate) for 3 consecutive days or on d 45 of the study, whichever came first. Calves had ad libitum access to starter and water throughout the study. Feed intake as well as fecal and respiratory scores were recorded daily; body weight, withers height, and hip height were recorded weekly. Gross rumen measurements and rumen samples for future gross and histological analyses were taken at 4 and 8 wk. All calves grew similarly; weaning age averaged $40.39 \pm 0.77 \mathrm{~d}$. Lifetime average daily gain was $0.60 \pm 0.05 \mathrm{~kg} / \mathrm{d}$ and lifetime gainto-feed ratio was $0.56 \pm 0.05$. Milk replacer, starter, total dry matter intake, gross and histological rumen measurements, rumen $\mathrm{pH}$, fecal and respiratory scores,

\footnotetext{
Received January 5, 2015.

Accepted May 26, 2015.

${ }^{1}$ Present address: Virginia Polytechnic Institute and State

${ }^{2}$ Corresponding author: danielsk@vt.edu
} University, Dairy Science Department, 2070 Litton-Reaves Hall, Blacksburg, 24061.
\end{abstract}

and total medical costs were not affected by treatment. Despite total medical costs not differing by treatment, a lower percentage of AMF calves were treated for respiratory ailments and respiratory treatment cost was lower for AMF compared with control. Several factors may have contributed to an overall lack of observed treatment effect in this study, including include the use of a low-forage (compared with concentrate) diet, immunocompetent calves, and the selected product dose and routes of delivery. Dietary inclusion $(2 \mathrm{~g} / \mathrm{d})$ of an extract of $A$. oryzae did not affect calf growth, intake, and ruminal or health measurements.

Key words: dairy calf, growth, prebiotic, Aspergillus oryzae

\section{INTRODUCTION}

Amaferm is a commercially prepared and marketed fermentation extract of the fungus Aspergillus oryzae (Biozyme Inc., St. Joseph, MO). It can be used as a prebiotic in calf feed (Beharka et al., 1991), but has more commonly been used in sheep and beef finishing diets (Schmidt et al., 2004; Zerby et al., 2011). Aspergillus oryzae has long been used in the Japanese food industry for fermenting foods such as saki, soy sauce, and miso, and it is regarded as safe because it does not produce aflatoxin (Uchida et al., 2006). The commercially available fermentation extract of $A$. oryzae is not living, therefore it is known to function as a prebiotic as opposed to a probiotic.

Over $20 \mathrm{yr}$ ago, it was reported that dietary inclusion of a fermentation extract of $A$. oryzae hastened weaning, increased ruminal bacteria numbers, and increased rumen fermentative activity in young Holstein calves (Beharka et al., 1991). Calves in that study were fed milk at $8 \%$ of birth weight, $16.6 \% \mathrm{CP}$ starter, and a mixture of alfalfa and bromegrass hay (Beharka et al., 1991). Currently, the NRC does not recommend dietary forage for preweaned dairy calves, and instead recommends calf starter (NRC, 2001). The $A$. oryzae fermentation extract is noted to increase fiber digestibility (Beharka et al., 1991), and thus benefits to forage-fed calves seems likely. It is not known if a 
fermentation extract of $A$. oryzae added to modern calf diets that are not high in forage would be of benefit. The rationale for thinking that it might be efficacious, apart from effects on fiber digestibility, is that it has been observed that addition of a fermentation extract of $A$. oryzae promotes growth of the naturally occurring population of ruminal Megasphaera elsdenii (Waldrip and Martin, 1993). Promoting M. elsdenii growth in the rumen is of potential interest due to the ability of $M$. elsdenii to use lactate as substrate (Counotte et al., 1981). Lactate is abundant in dairy calf rumens and contributes to low ruminal $\mathrm{pH}$ (Anderson et al., 1987a,b); M. elsdenii can ferment lactate and produce butyrate (Counotte et al., 1981). Butyrate is widely reported to have growth effects on rumen epithelial cells (Sander et al., 1959; Sakata and Tamate, 1978; Shen et al., 2004; Gorka et al., 2009; Malhi et al., 2013). The bacterial population shift in $M$. elsdenii that can occur with feeding an extract of $A$. oryzae, as well as downstream effects on butyrate production, make use of this prebiotic attractive, especially because an increased butyrate concentration in the rumen may promote rumen development and improve feed utilization by the calf to promote somatic growth. Another reason that dietary inclusion of a fermentation extract of $A$. oryzae in calf diets may be beneficial comes from the idea that prebiotics may improve gut health by decreasing incidence and duration of enteritis and diarrhea. Therefore, we wished to reinvestigate the efficacy of a fermentation extract of $A$. oryzae in hastening weaning and affecting calf growth and health, as well as affecting rumen development. The objective of the current study was to assess whether addition of a fermentation extract of $A$. oryzae supplemented at $2 \mathrm{~g} / \mathrm{d}$ as well as calf age would affect BW, hip height $(\mathbf{H H})$, withers height (WH), ADG, feed efficiency, intake, weaning age, gross and histological rumen measurements, rumen $\mathrm{pH}$, and health measurements in Holstein bull calves.

\section{MATERIALS AND METHODS}

\section{Calves and Treatments}

The Ohio State University Animal Care and Use Committee approved all animal procedures (protocol \#2013A00000059). In this 8-wk study, 56 locally sourced (Wayne County, $\mathrm{OH}$ ) Holstein bull calves were purchased and transported to the OARDC Small Ruminant Research Center (Wooster, OH) on May 6, 2013. Upon arrival, calves were blocked by source farm $(\mathrm{n}=13)$, age (0 to $6 \mathrm{~d}$ of age), initial BW, initial $\operatorname{IgG}$ score, and lactation number of dam (primiparous or multiparous). All calves in our experiment had successful passive transfer of immunity $(>10 \mathrm{mg} / \mathrm{mL}$ of serum
IgG; Weaver et al., 2000); blocking removed potential bias due to actual serum IgG concentration. Calves were randomly assigned to a slaughter age $[4 \mathrm{wk}$ (n $=16)$ or $8 \mathrm{wk}(\mathrm{n}=36)]$, treatment $[$ control $(\mathbf{C O N}$; $\mathrm{n}=29$ ) or Amaferm (AMF; $\mathrm{n}=27$ )], and side of the barn (east/expanded metal flooring, $\mathrm{n}=20$; west/ plastic flooring, $\mathrm{n}=36$ ). Final number of calves for each treatment were: CON, $\mathrm{n}=8$ (4 wk) and 19 ( $8 \mathrm{wk})$; AMF, n $=8$ ( $4 \mathrm{wk})$ and 17 ( $8 \mathrm{wk}$ ). During the first 3 wk of the study, 3 AMF calves died; at that point, the 2 replacement AMF calves were used, resulting in a final number of 25 calves on the AMF treatment. One CON calf assigned to the wk 4 slaughter date was not eligible for slaughter at wk 4 due to medication withdrawal constraints; therefore, 1 CON replacement calf was slaughtered in its place at wk 4 and the original wk-4 calf was slaughtered at wk 8 and its data were retained in the final data set. It is believed these deaths were not related to the treatment, considering they occurred very early in the study when very little product had been administered to the calves and because 2 calves had died previously, before the study had started before final treatments were assigned. Side of barn was included as a blocking factor to account for potential variation due to circumstances unique to each side of the barn. Compared with the west side, the east side had more hours of natural sunlight per day, potentially elevated ambient temperature, and expanded metal flooring (as opposed to plastic).

\section{Housing and Feeding}

Calves were individually housed and fed in a naturally ventilated sidewall curtain barn. Pens had no bedding; the experimental unit was calf. Calves were fed a 22\% CP, 20\% fat (as fed basis) nonmedicated milk replacer (MR; Amplifier Max; Land O'Lakes Animal Milk Products Co., Arden Hills, MN) from buckets twice daily at 0600 and $1800 \mathrm{~h}$. Calves were offered $0.68 \mathrm{~kg}$ of MR powder mixed in $3.78 \mathrm{~L}$ of water per day; MR was delivered in 2 equal portions. Calves assigned to AMF received $2 \mathrm{~g} / \mathrm{d}$ of liquid fermentation extract of $A$. oryzae product (Biozyme Inc.; $0.4 \%$ minimum CP, $0.0 \%$ minimum crude fat, $2.0 \%$ maximum crude fiber, $1.0 \%$ maximum ADF guaranteed analysis; $2 \mathrm{~g}$ $=\$ 0.026)$, delivered in equal portions of MR for the first $4 \mathrm{wk}$ of the study. Calves had free choice access to a medicated (0.0033\% Decoquinate) $20 \%$ CP (as-fed basis) texturized calf starter (Purina Commercial Calf; Purina Mills LLC, St. Louis, MO) and water at all times. Drinking water was treated with $1 \mathrm{mg} / \mathrm{L}$ of OxyMer (Oxxion, Eden Prairie, MN), which is a chlorine dioxide solution. It was used here for water sanitation in the same way that municipal water is treated. Fur- 
thermore, in efforts to minimize risk of developing and spreading bacterial pneumonia, OxyMer (25 ppm) was also included in the initial feeding of oral electrolytes given to the calves upon arrival as a prophylactic. For the final $4 \mathrm{wk}$ of the study, dry fermentation extract of A. oryzae product (Biozyme Inc.; $14.0 \%$ minimum $\mathrm{CP}, 1.6 \%$ minimum crude fat, $14.0 \%$ maximum crude fiber, $18.0 \%$ maximum ADF; $2 \mathrm{~g}=\$ 0.026)$ was topdressed on calf starter $(2 \mathrm{~g} / \mathrm{d}$; offered at $0600 \mathrm{~h}$ feeding). Calves began the 5 -d weaning process when they consumed $0.91 \mathrm{~kg}$ of starter for 3 consecutive days or on d 45 of the study, whichever came first. All wk-4 calves remained on MR until slaughter. During the weaning process, MR amount was reduced by $50 \%$ and was offered at the $0600 \mathrm{~h}$ feeding only. Calf starter and MR intake were measured daily.

\section{Growth Measurements and Health Monitoring}

All calves were weighed and measured upon arrival and weekly thereafter for BW, HH, and WH. Scheduled vaccinations were administered upon arrival and throughout the study. Upon arrival and approximately $7 \mathrm{~d}$ after arrival, calves were vaccinated against infectious bovine rhinotracheitis virus and parainfluenza 3 intranasally with treatment of $1 \mathrm{~mL} /$ nostril of Inforce-3 (Zoetis, Florham Park, NJ). Upon arrival and 4 and 6 $\mathrm{d}$ after arrival, calves were vaccinated against bovine respiratory disease (BRD) subcutaneously with treatment of $2 \mathrm{~mL}$ of Excenel (Zoetis). Lastly, approximately $5 \mathrm{~d}$ after arrival (and $26 \mathrm{~d}$ for wk- 8 calves only), calves were vaccinated to prevent clostridial infections with treatment of $2 \mathrm{~mL}$ of Ultrachoice 7 (Zoetis) administered subcutaneously.

A 4-point scale was used for twice-daily fecal scoring (Diaz et al., 2001). In this system, scores were as follows: $1=$ firm, well-formed (not hard), $2=$ soft, pudding-like, $3=$ runny, pancake batter, and $4=$ liquid, splatters. Calves were scored before feeding commenced. Any calf with a fecal score of 3 or greater was offered $1.89 \mathrm{~L}$ (93 $\mathrm{g}$ of electrolyte powder dissolved in $1.89 \mathrm{~L}$ of water) of oral electrolytes (Electrolyte Complete; Land O'Lakes Inc., Shoreview, MN) until diarrhea subsided; oral electrolyte solution was offered up to twice daily within $2 \mathrm{~h}$ of feeding. A 4-point scale was also used for twice daily respiratory scoring, where $1=$ calf breathing at a normal rate; 2 = calf not showing signs of distress, but an observable increase in breathing rate compared with 1; 3 = labored calf breathing with other signs of respiratory infection (lethargy, nasal discharge, and so on); and $4=$ score of 3 plus rectal temperature greater than or equal to $39.4^{\circ} \mathrm{C}$. Calves were scored before feeding commenced. Any calf with a respiratory score of 3 or greater was flagged for a more extensive examination after feeding. If warranted, appropriate therapeutic intervention was taken. Medical treatment decisions were based on clinical signs and slaughter withhold requirements. Suspected BRD infections were treated under the advisement of the attending OARDC veterinarian primarily with injectables: Excenel (Zoetis) administered via subcutaneous route $(2 \mathrm{~mL} / 45.36 \mathrm{~kg})$; Draxxin (Zoetis) administered via subcutaneous route (1.1 $\mathrm{mL} / 45.36 \mathrm{~kg}$ ); Nuflor (Merck Animal Health, Summit, NJ) administered via intramuscular route $(3 \mathrm{~mL} / 45.36$ $\mathrm{kg}$ ); and Sustain III calf boluses (Bimeda Inc., Oakbrook Terrace, IL) administered orally (2 boluses $/ 45.36$ kg). Prevail (Vetone, MWI Veterinary Supply, Boise, ID) was used for control of pyrexia (rectal temperature $\geq 39.4^{\circ} \mathrm{C} ; 2 \mathrm{~mL} / 45.36 \mathrm{~kg}$ administered intravenously) associated with BRD and endotoxemia.

\section{Sample Collection of Rumen Tissue and Content}

For slaughter, animals were transported to the meat science laboratory at The Ohio State University. Feed was not withheld before slaughter. Calves, either assigned to the wk 4 or 8 groups, were slaughtered by captive-bolt stunning followed by exsanguination. The entire gastrointestinal tract was ligated, removed, and weighed full. The full forestomach was dissected from the intestines, reweighed, and then dissected at the reticulo-omasal orifice and weighed again. The rumen was then opened and its content was collected for immediate $\mathrm{pH}$ measurement. Rumen samples intended for morphology analyses were obtained from the cranial ventral location on the right side within each washed rumen using a punch biopsy tool with an internal diameter of $2.54 \mathrm{~cm}$. Samples were stored in PBS $(\mathrm{pH}$ 7.4) at $4^{\circ} \mathrm{C}$ overnight. The next day, 10 representative papillae were plucked from each cranial ventral biopsy sample, attached to $2 \mathrm{~mm}$ of graphing paper using clear tape, and photographed. The length and 2-dimensional area of each papilla was measured using the CellSens software (Olympus, Tokyo, Japan) according to the method of Puch et al., (2012). Averaged values from 10 papillae were then reported as papillae width and length for each calf. Rumen punch biopsy samples were also used to determine weights of the epithelium and the wall of the rumen. For this analysis, the epithelium was separated from the wall using forceps and weighed. Priority was given to the cranial ventral region because it has the highest blood flow rate per tissue area in the rumen (Von Engelhardt and Hales, 1977).

\section{Rumen Histological Measurements}

Representative rumen tissue samples from the cranial ventral section of each rumen were used for histologi- 
cal staining. This included removal from $70 \%$ ethanol storage, cutting a 0.5 -cm wide section out, and placing the cut section into a labeled histology cassette, and additional storage in $70 \%$ ethanol until further processing. Samples were submitted to the Histology/IHC Department of the Comparative Pathology and Mouse Phenotyping Shared Resource (The Ohio State College of Veterinary Medicine, Columbus, $\mathrm{OH}$ ) for routine processing, embedding in paraffin, and sectioning (5$\mu \mathrm{m}$ thick sections mounted onto positively charged microscope slides). Microscope slides were brought back to the laboratory, and 1 slide per animal was subjected to Masson's Trichrome staining. The stained tissues were deparaffinized using xylene and hydrated $(100 \%$ ethanol, then $95 \%$ ethanol, then $70 \%$ ethanol, then distilled water). After the slides were hydrated they were stained as follows: mordant in Bouin's solution at $56^{\circ} \mathrm{C}$ for $15 \mathrm{~min}$, washed with tap water for $1 \mathrm{~min}$, stained in Weigert's iron hematoxylin solution (stains nucleus dark purple) for 5 min, washed with tap water for $2 \mathrm{~min}$, dipped in distilled water for $15 \mathrm{~s}$, stained in Biebrich scarlet-acid fuchsin solution (stains cytoplasm red or pink) for $5 \mathrm{~min}$, dipped in distilled water for $15 \mathrm{~s}$, placed in phosphotungstic and phosphomolybdic acid solution for $5 \mathrm{~min}$, stained in aniline blue solution (stains connective tissue blue) for 5 min, placed in $1 \%$ acetic acid solution for $2 \mathrm{~min}$, then dipped in distilled water for $15 \mathrm{~s}$. After the staining process was complete, the slides were dehydrated (95\% ethanol, then $100 \%$ ethanol, then xylene) and mounted using permaslip and a coverslip over the newly stained tissue.

\section{Medical Cost Estimates}

Retail cost of each therapeutic agent was obtained from MWI Veterinary Supply (Boise, ID) in the summer of 2013, except for the cost of oral electrolytes, which was obtained from Town and Country Co-op (Wooster, $\mathrm{OH})$. Costs were as follows: Inforce-3 $(\$ 0.55 /$ $\mathrm{mL})$, Excenel $(\$ 0.73 / \mathrm{mL})$, Ultrachoice $7(\$ 0.26 / \mathrm{mL})$, Draxxin $(\$ 3.90 / \mathrm{mL})$, Nuflor $(\$ 0.62 / \mathrm{mL})$, Sustain III (\$0.79/bolus), and oral electrolytes (\$1.54/93-g dose). Medical costs were calculated on a per-calf basis and total medical cost per calf was used for data analysis.

\section{Feed Sampling and Analysis}

Daily feed intake was calculated by subtracting the refusal for both starter and MR from the starter and MR offered. Fresh starter and MR samples were collected once weekly for DM analysis. Starter refusals were collected daily from each calf. For the first 4 wk of the study, a single composite sample of refused starter was collected for DM analysis. For the final 4 wk of the study, starter refusals were composited by treatment (CON or AMF) before DM analysis. Starter samples used to calculate DM were weighed and then placed in an oven set at $50^{\circ} \mathrm{C}$ for $24 \mathrm{~h}$. After $24 \mathrm{~h}$, the samples were taken out, weighed, and the DM content was determined. The MR samples were analyzed for DM content by weighing each sample and then heating in an oven at $100^{\circ} \mathrm{C}$ for $5 \mathrm{~h}$ (Bowen Yoho et al., 2013). Samples were cooled in a desiccator until they reached room temperature and then weighed again to determine DM content. Dry matter intake was determined by standard calculations.

\section{Environmental Factors}

Ambient barn temperature and relative humidity were digitally logged every hour throughout the duration of the experiment. Two loggers (model number EL-USB-2+; Lascar Electronics, Whiteparish, Salisbury, UK) were used; one was placed in an empty pen at the midway point of the east side of the barn and the other was placed in an empty pen at the midway point of the west side of the barn. Each logger was positioned $80 \mathrm{~cm}$ above the flooring to approximate conditions for standing calves. Loggers remained in place for the duration of the study; data were downloaded after the study ended and compiled using EL-WIN-USB data logging software (Lascar Electronics). Temperature and humidity data were downloaded from the loggers and used to calculate the temperature-humidity index $(\mathbf{T H I})$, where THI $=0.8 \times$ ambient temperature + $[(\%$ relative humidity $/ 100) \times($ ambient temperature 14.4)] + 46.4 (Davis et al., 2003).

\section{Statistical Analysis}

All data were analyzed using the MIXED procedure of SAS (version 9.2; SAS Institute Inc., Cary, NC). Intake, growth, fecal, and respiratory data were analyzed using the repeated measure of week and fixed effects of treatment, side of the barn, and their interactions. An autoregressive covariance structure $[\mathrm{AR}(1)]$ was used for intake and growth data. Calf within treatment, slaughter age, and side of the barn were the random effects for each mixed model.

Rumen measurements for $\mathrm{pH}$, full rumen and empty rumen weights, rumen biopsy weights, and rumen tissue thickness measurements (tunica submucosa and tunica muscularis) data were analyzed with a statistical model that included the fixed effects of treatment, slaughter age, side of the barn, and their 2- and 3-way interactions. Calf within treatment, slaughter age, and side of the barn were the random effects. 
Rumen papillae length and width were analyzed using a model that contained only treatment, floor, and treatment $\times$ floor interaction as fixed effects; this was due to only wk- 8 calves being evaluated for these dependent variables. The random effect in this model was calf within treatment and floor.

Side of the barn was included as a fixed model effect in all variance models because there were different flooring types on the east and west sides of the barn (expanded metal and slatted plastic, respectively). It was unknown if flooring would affect experimental measurements. We accounted for this potential source of variation in our statistical models but do not report side of barn effects here because there were none. However, this fixed effect interacted with all other fixed effects in the model and thus partitioned away from the residual error term in our reported results. Least squares means \pm standard error of the means are reported unless otherwise noted. Significance was declared when $P \leq 0.05$. Last, all data were subjected to a correlation analysis using the CORR procedure in SAS.

\section{RESULTS AND DISCUSSION}

\section{Route of AMF Administration}

In our study, we chose to administer the treatment, $\mathrm{AMF}$, in the liquid portion of the calf's diet for the first $4 \mathrm{wk}$ of the study, and topdressed AMF on the starter for the final $4 \mathrm{wk}$ of the study. We chose to do this because voluntary starter intake is low in the first weeks of life and we wished to ensure that the entire 2-g daily dose was consumed every day. Metabolism of AMF is likely different in periruminants administered a feed additive either in the liquid or solid portion of the diet. This is due to the function of the reticular (esophageal) groove, which regulates the passage of feed into the rumen in young calves. When calves drink milk from either a teat, bottle, or bucket, the conditioned reflexive closure of the reticular groove occurs (Orskov, 1972). This shunts milk past the reticulo-rumen into the abomasum and keeps the consumed milk or MR from being fermented in the rumen. Dry feed consumption and spillage of milk or MR, which are not associated with closure of the reticular groove, are the only means for feed to enter the rumen and be subjected to ruminal fermentation. Less than $3 \%$ of MR consumed at a given meal is expected to enter the rumen (Toullec and Guilloteau, 1989). So, whereas the dose was constant for calves on AMF, the quantity of product that arrived at the rumen and lower gastrointestinal tract were likely different depending on whether or not the AMF was administered with the liquid or solid portion of the meal. We did not attempt to measure ruminal recovery of orally dosed AMF at any time in our study.

\section{Feed Intake}

Table 1 shows MR, starter, total DMI, and gain-tofeed ratio results. Meal replacer, starter, and total DMI did not differ by the 2-way interaction of treatment $\times$ week or the main effect of treatment. There was a difference in MR and starter DMI for week $(P<0.001)$, which showed both linear and quadratic characteristics. For MR DMI this can be explained by the linear increase in intake up until around wk 6 , when some calves started to wean, which explains the quadratic nature of the curve, and by wk 8 , when all calves were weaned. As for starter DMI, the linear increase is apparent throughout, but a large increase of starter between wk 4 and 5 (2.47 $\mathrm{kg}$ compared with $0.44 \mathrm{~kg}$ between wk 3 and 4) was noted, which aids in explaining the quadratic relationship present. Total DMI showed both linear and quadratic affects $(P<0.05)$, which follows the same patterns exhibited in MR and starter DMI.

In our study the average MR, starter, and total DMI for calves at wk 8 were $0.48 \pm 0.005,0.57 \pm 0.03$, and $1.06 \pm 0.02 \mathrm{~kg} / \mathrm{d}$, respectively. These DMI values are similar to the values found by Hill et al. (2008) for MR (19.8 and $21.1 \%$ fat DM), starter $(20.3 \% \mathrm{DM})$, and total DMI in Holstein heifers fed similar diets that were $0.44,0.57 \pm 0.05$, and $1.00 \pm 0.05 \mathrm{~kg} / \mathrm{d}$, respectively.

Growing calves will gradually increase voluntary starter intake over time and although no set standard for weaning exists, Davis and Drackley (1998) noted that when grain intake increases from 0.79 to $0.91 \mathrm{~kg} / \mathrm{d}$ and $\mathrm{BW}$ is around 54 to $59 \mathrm{~kg}$ the calf will be consuming enough starter to support maintenance energy plus gain needs. In our study, calves began the 5 -d weaning process when they consumed $0.91 \mathrm{~kg}$ of starter for 3 consecutive days or on d 45 of the study, whichever came first. Weaning age did not depend on treatment $(P=0.988)$ and averaged $40.38 \pm 0.77 \mathrm{~d}$ for CON and $40.40 \pm 0.77 \mathrm{~d}$ for AMF calves. Knowing that starter intake was not different between treatments, it comes as no surprise that no treatment difference in weaning age was observed in our study. Beharka et al. (1991) noted an earlier weaning age of about $1 \mathrm{wk}$ in calves supplemented with a fermentation extract of $A$. oryzae (in all 3 supplemental levels: $0.92,1.83$, or $5.5 \mathrm{~g} /$ $\mathrm{kg}$ of starter), and the increase in dry feed intake for the treatment groups in that study helps explain the results.

Whereas Beharka et al. (1991) noticed an increase in dry feed intake of calves fed different amounts of fermentation extract of $A$. oyrzae (average dry feed intake 


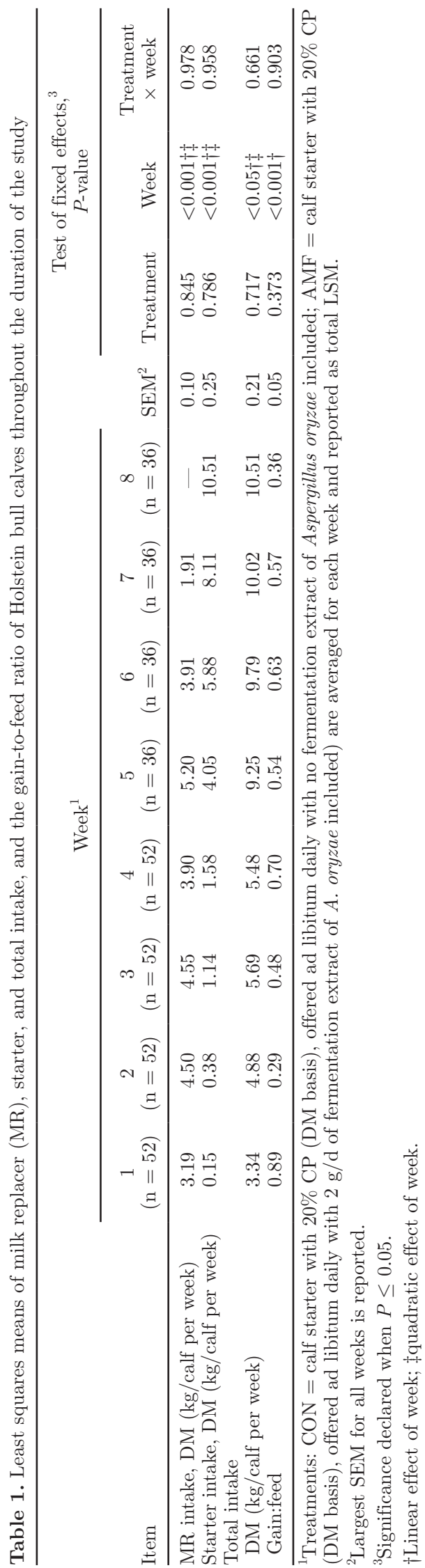

of $1.3 \pm 0.11 \mathrm{~kg} / \mathrm{d}$ between the 3 groups) compared with control calves $(1.0 \pm 0.10 \mathrm{~kg} / \mathrm{d})$, this difference did not translate to an increase in gain-to-feed ratio, which did not differ between any groups in that study. The average gain-to-feed ratio of all calves in our study was $0.56 \pm 0.05$, which was higher than calves fed a similar diet (0.36) in the study by Hill et al. (2008). In our study, gain-to-feed ratio was not static for the duration of the experiment (Table 1), meaning calves were more efficient at utilizing feed for gain in certain weeks of the study compared with others. Both DMI and environmental factors likely affected gain-to-feed ratio values here.

\section{Growth Measurements}

We hypothesized that BW, WH, HH, and ADG would each be affected by calf age, treatment, or the interaction of age and treatment. Table 2 shows the results for BW, WH, HH, and ADG. Average initial BW (42.60 $\pm 0.60 \mathrm{~kg}), \mathrm{WH}(78.15 \pm 0.26 \mathrm{~cm})$, and $\mathrm{HH}(81.72 \pm$ $0.26 \mathrm{~cm}$ ) did not differ between treatments as planned. Likewise, average age of calves at initiation of the study was also not different $(P=0.788)$ between treatments $(2.82 \pm 0.34 \mathrm{~d})$. Body weight, WH, HH, and ADG did not by differ 2 -way interaction of treatment $\times$ week or the main effect of treatment. However, a difference was noted for week for $\mathrm{BW}, \mathrm{WH}$, and $\mathrm{HH}(P<0.001)$, showing both linear and quadratic characteristics. Considering intake data showed both linear and quadratic relationships, it seems fitting that growth measurements would also be affected accordingly. Increases in $\mathrm{BW}, \mathrm{WH}$, and $\mathrm{HH}$ would be expected as the calves get older and consumed more dry feed, but no evidence suggested that addition of a fermentation extract of $A$. oryzae to the diet increased calf growth. Average daily gain followed the same pattern as gain-to-feed ratio and showed a linear effect of week $(P<0.001)$, but as with gain-to-feed ratio this is not easily explained. Hill et al. (2008) fed Holstein heifer calves a similar MR (19.8 and $21.1 \%$ fat $\mathrm{DM})$ and starter $(20.3 \% \mathrm{DM})$ diet and reported ADG of $0.37 \pm 0.01 \mathrm{~kg} / \mathrm{d}$ over a 9 -wk period, which is much lower than the average from our study of $0.60 \pm 0.05 \mathrm{~kg} / \mathrm{d}$ over an 8 -wk period. The reason for such a drastic difference in ADG between the studies is not immediately obvious and may involve overall calf health, seasonal effects, or both, because DMI was nearly the same (discussed in more detail below).

Beharka et al. (1991) fed a fermentation extract of $A$. oryzae to Holstein heifers fed a $16.6 \% \mathrm{CP}$ starter diet with access to $75 \%$ bromegrass and $25 \%$ alfalfa hay and found through 2 experiments that calves with an average intake of $2.2 \mathrm{~g} / \mathrm{d}$ of a fermentation extract of $A$. 
oryzae over a 10-wk lifetime experienced ADG of 0.58 $\pm 0.16 \mathrm{~kg} / \mathrm{d}$. This is comparable to the calves in our study $(0.60 \pm 0.03 \mathrm{~kg} / \mathrm{d})$, but the absence of hay fed in the current study and the increased $\mathrm{CP}$ content in the starter complicate any comparisons made between the experiments. Also, Beharka et al. (1991), reported differences in ADG between calves fed an extract of $A$. oryzae, and those not offered the extract in a third experiment, with control calves experiencing $0.49 \pm$ $0.10 \mathrm{~kg} / \mathrm{d}$ of ADG compared with $0.60 \pm 0.11 \mathrm{~kg} / \mathrm{d}$ of ADG for calves fed a fermentation extract of $A$. oryzae over a 10 -wk period.

Ambient temperatures and THI were obtained for each side of the barn; these did not differ, so coincident values were averaged for reporting purposes. The overall average temperature was $19.34 \pm 0.61^{\circ} \mathrm{C}$ and overall average THI was $65.31 \pm 0.92$ (Figure 1 ). The overall average temperature of $19^{\circ} \mathrm{C}$ falls within the thermoneutral zone of 15 to $25^{\circ} \mathrm{C}$ for Holstein dairy calves that are at least 3 wk old (Gebremendhin et al., 1981). However, examination of only average ambient temperature throughout the barn for the entire 8-wk duration of our study neglects actual periods of coldand heat-stress for growing calves. Although it is true that, on average, calves were not exposed to thermal stress, they experienced definite periods of both cold and heat stress.

Davis and Drackley (1998) summarized the work of several groups and reported that the lower critical temperature (LCT) for calves younger than 1 wk of age is in the range of 13 to $20^{\circ} \mathrm{C}$ and declines with age. They note the LCT for a 15 -d-old calf to be $9.5^{\circ} \mathrm{C}$, whereas for a 30-d-old calf it is $6.4^{\circ} \mathrm{C}$. (Davis and Drackley, 1998). Once the ambient temperature falls below the LCT, the calf must use physical (e.g., vasoconstriction) and chemical (e.g., thermogenesis) means to reduce heat loss and, if an option, may also compensate by increasing DMI to elevate heat load. During the second week of the study, ambient temperature reached as low as $4^{\circ} \mathrm{C}$ and averaged about $9^{\circ} \mathrm{C}$ (whereas the low THI reached as low as 42 and averaged about 48 for the entire 7-d period; Figure 1). This is near or below the lower limit of the thermoneutral zone for 2-wk-old Holstein calves. During periods of cold stress, many animals compensate by increasing voluntary DMI, as has been observed by Scott et al. (1993). Very young calves may be less apt to do this, as appears to be the case here (Table 1). We report that ADG for all calves $(\mathrm{n}=52)$ in wk 2 was $0.20 \pm 0.02 \mathrm{~kg} / \mathrm{d}$, compared with $0.41 \pm 0.03$ and $0.63 \pm 0.03 \mathrm{~kg} / \mathrm{d}$ for wk 3 and 4 , respectively (Table 1). Other factors besides cold stress may have contributed to this decrease in ADG at wk 2 compared with wk 3 and 4 . As discussed later, 

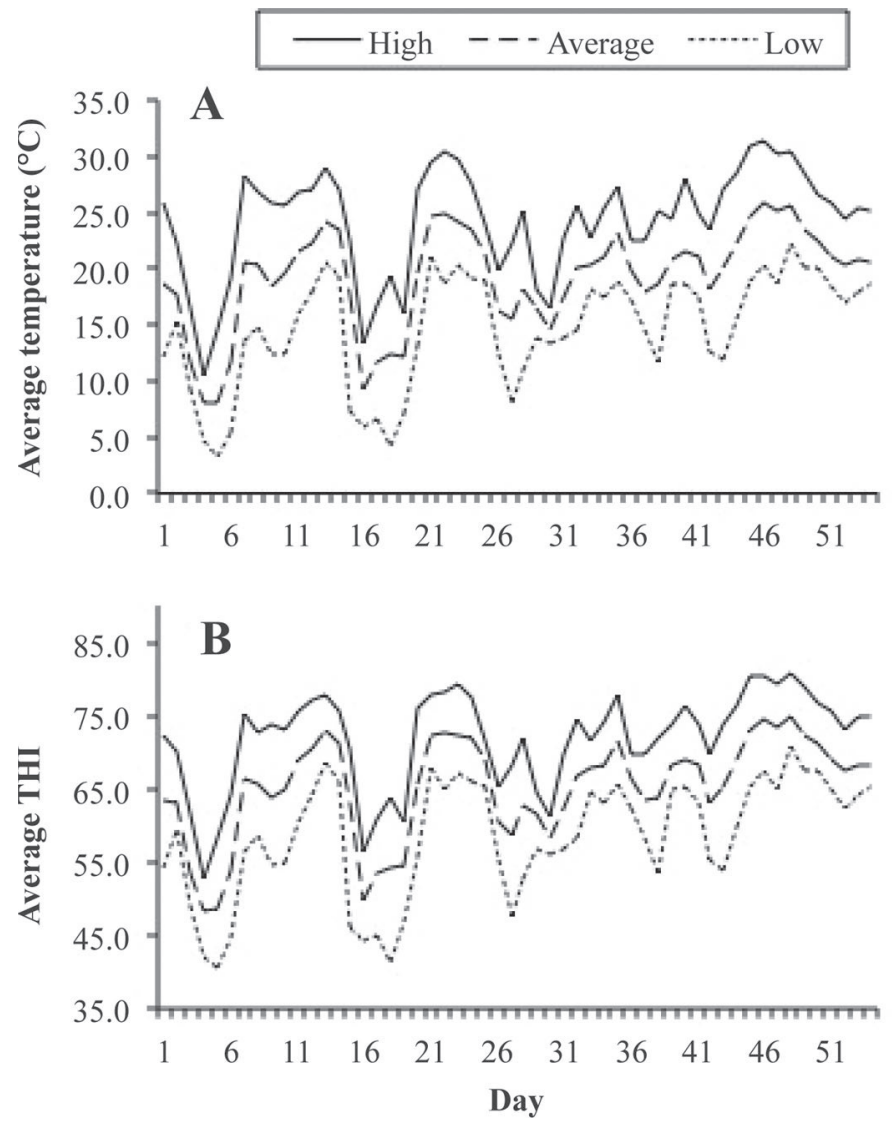

Figure 1. Average temperature $\left({ }^{\circ} \mathrm{C} ; \mathrm{A}\right)$ and temperature-humidity index (THI; B) of the barn for every day during the study. Low, high, and average temperatures and low, high, and average humidity were recorded using a temperature logger (model number EL-USB-2+; Lascar Electronics, Whiteparish, Salisbury, UK) and converted into Celsius and THI data. THI $=0.8 \times$ ambient temperature $+[(\%$ relative humidity/100) $\times($ ambient temperature -14.4$)]+46.4$ (Davis et al., 2003). Day 1 corresponds to May 9, 2013.

increased incidence of diarrhea was noted during wk 2 compared with the later 2 wk.

Ambient temperatures at or above $26^{\circ} \mathrm{C}$ are outside of the thermoneutral zone for dairy calves (Davis and Drackley, 1998). In times of heat stress, the calf must expend energy to cool itself; this mainly involves panting and reduced DMI. O'Brien et al. (2010) found Holstein bull calves exposed to heat stress had a $12 \%$ decrease in DMI. In our study, ambient temperatures met or exceeded $26^{\circ} \mathrm{C}$ during wk 7 (Figure 1). In addition to indicating underlying respiratory disease, elevated respiration rate can also indicate thermal stress on an animal. On days with at least 1 ambient temperature reading above $26^{\circ} \mathrm{C}$, we did not notice corresponding increases in respiratory rate or decreases in DMI. This perhaps indicates that heat stress was not great in our study. However, other factors besides ambient temperature can affect the severity of heat stress.
These include humidity, wind speed, and radiant heat load. Measuring THI is useful in assessing heat stress. A THI of 68 is indicative of heat stress beginning to adversely affect cows (Zimbelman et al., 2009) and a THI $\geq 83$ indicates severe heat stress (Coleman et al., 1996). Here, the average THI throughout both barns was $65.31 \pm 0.92$ for the entire duration of the study. The highest THI recorded during this study was 80, which happened during the same days of elevated temperature. Had we not collected the THI data, we would have been less able to explain the observed patterns in ADG. Regardless of the treatments imposed during our study, observed effects of THI on calf growth are worthy of documentation.

\section{Rumen $\mathrm{pH}$ and Mass}

Rumen $\boldsymbol{p H}$. In our study, rumen $\mathrm{pH}$ depended on age but not treatment or the interaction of age and treatment (Table 3 ). Rumen $\mathrm{pH}$ was higher at $8 \mathrm{wk}$ $(6.18 \pm 0.15)$ than at $4 \mathrm{wk}(5.64 \pm 0.15)$ of age $(P<$ $0.001)$; this evolution of rumen $\mathrm{pH}$ is common in dairy calves and is associated with dynamism of lactate and VFA concentrations in the rumen. Had pH been dependent on treatment, we would have explored the reason for this by measuring lactate and VFA concentrations, as well as the abundance of ruminal $M$. elsdenii. Our original thought was that feeding a fermentation extract of $A$. oryzae might promote growth of the naturally occurring population of ruminal M. elsdenii (Waldrip and Martin, 1993), which in turn could conceivably affect lactate utilization, VFA concentrations, rumen $\mathrm{pH}$, and perhaps even rumen papillae growth if VFA production was shifted toward butyrate. Measurement of $\mathrm{pH}$ is the easiest of those measurements to perform; lack of treatment effect on rumen $\mathrm{pH}$ was disappointing and we think that this led to many of our other observations not being statistically significant either. However, despite no treatment differences, the rumen $\mathrm{pH}$ measurements we obtained were in the normal range for dairy calves that are either supplemented or not with a fermentation extract of $A$. oryzae (Anderson et al., 1987a; Beharka et al., 1991; Li et al., 2012).

Rumen Mass. Full and empty rumen mass depended on age but not treatment or the interaction of age and treatment (Table 3). As expected, empty rumen mass was higher at $8(1.32 \pm 0.05 \mathrm{~kg})$ than at $4 \mathrm{wk}$ $(0.52 \pm 0.05 \mathrm{~kg})$ of age $(P<0.001)$. The same patterns were observed when full and empty rumen masses were expressed as percentages of BW (Table 3). Regardless of treatment, at $4 \mathrm{wk}$ of age the empty rumen represented $0.94 \pm 0.08 \%$ of BW and $1.76 \pm 0.08 \%$ of BW at 8 wk (Table 3). Our findings regarding rumen mass are similar to reports with 10- (Khan et al., 2008) and 
Table 3. Gross rumen and papillae measurements of Holstein bull calves taken at the 2 slaughter points in the study

\begin{tabular}{|c|c|c|c|c|c|c|}
\hline \multirow[b]{2}{*}{ Item } & \multicolumn{2}{|c|}{ Slaughter time point ${ }^{1}$} & \multirow[b]{2}{*}{ SEM } & \multicolumn{3}{|c|}{ Test of fixed effects, ${ }^{2} P$-value } \\
\hline & $\begin{array}{c}4 \mathrm{wk} \\
(\mathrm{n}=52)\end{array}$ & $\begin{array}{c}8 \mathrm{wk} \\
(\mathrm{n}=36)\end{array}$ & & Treatment & Age & $\begin{array}{l}\text { Treatment } \\
\times \text { age }\end{array}$ \\
\hline Rumen pH & 5.64 & 6.18 & 0.15 & 0.634 & $<0.001$ & 0.670 \\
\hline Full rumen (kg) & 1.81 & 5.29 & 0.42 & 0.418 & $<0.001$ & 0.586 \\
\hline Empty rumen (kg) & 0.52 & 1.32 & 0.05 & 0.881 & $<0.001$ & 0.579 \\
\hline Full rumen ( $\%$ of BW) & 3.25 & 7.07 & 0.52 & 0.285 & $<0.001$ & 0.637 \\
\hline Empty rumen (\% of BW) & 0.94 & 1.76 & 0.08 & 0.821 & $<0.001$ & 0.523 \\
\hline \multicolumn{7}{|l|}{ Rumen biopsy weight ${ }^{4}(\mathrm{mg})$} \\
\hline Epithelium & 1.78 & 2.96 & 0.10 & 0.597 & $<0.001$ & 0.804 \\
\hline Wall & 1.59 & 1.71 & 0.08 & 0.342 & 0.245 & 0.222 \\
\hline \multicolumn{7}{|l|}{ Rumen papillae $^{5}(\mathrm{~mm})$} \\
\hline Width & - & 1.56 & 0.05 & 0.840 & - & - \\
\hline Length & - & 4.70 & 0.19 & 0.588 & - & - \\
\hline \multicolumn{7}{|l|}{ Rumen wall thickness ${ }^{5}(\mathrm{~mm})$} \\
\hline Submucosa & 0.25 & 0.58 & 0.06 & 0.977 & $<0.001$ & 0.382 \\
\hline Tunica muscularis & 0.89 & 1.10 & 0.10 & 0.706 & 0.019 & 0.354 \\
\hline
\end{tabular}

${ }^{1}$ Treatments: $\mathrm{CON}=$ calf starter with $20 \% \mathrm{CP}$ (DM basis), offered ad libitum daily with no fermentation extract of Aspergillus oryzae included; AMF = calf starter with $20 \% \mathrm{CP}$ (DM basis), offered ad libitum daily with $2 \mathrm{~g} / \mathrm{d}$ of fermentation extract of $A$. oryzae included) are averaged for each time point and reported as total LSM.

${ }^{2}$ Significant declared when $P \leq 0.05$

${ }^{4}$ Epithelium and wall weights are from 2.54-cm-diameter rumen punch biopsies of cranial ventral location; epithelium and wall were separated using forceps and weighed separately.

${ }^{5}$ Measured in cranial ventral region.

11-wk-old (Beharka et al., 1998) calves. Interestingly when the 4 and 8 wk full and empty rumen masses of our study are plotted with the rumen masses from Khan et al. (2008) and Beharka et al. (1998), a linear relationship between both full and empty rumen weights is evident $\left(R^{2}=0.95\right.$ and 0.98 , respectively). These findings are corroborated with the positive correlation observed between full and empty rumen weights in our study $(\mathrm{r}=0.945, P=0.011)$. We suggest that as rumen fill increases, rumen tissue mass increases in a proportional and predictable manner in calves younger than 12 wk of age.

\section{Rumen Tissue Measurements}

Effects of Treatment. Just as rumen mass was unaffected by dietary inclusion of a fermentation extract of $A$. oryzae, so too was every rumen composition measurement we performed. These included proportion of rumen biopsy mass occupied by epithelium and wall, papillae area, thickness of ruminal submucosa, and thickness of ruminal tunica muscularis (Table 3). Had dietary inclusion of a fermentation extract of $A$. oryzae caused changes in measurements associated specifically with the rumen epithelium, we would have measured ruminal butyrate concentrations and, possibly, ketogenic gene expression in ruminal papillae. Nearly $90 \%$ of ruminal butyrate is oxidized to ketone form before entering the portal circulation. Ruminal butyrate is primarily oxidized to BHBA and, to a lesser extent, acetoacetate. Because of this change in form of butyrate, it is commonly viewed as an energy substrate for ruminal epithelial cells and is also implicated in ruminal papillae growth. Recently, Malhi et al. (2013) observed stimulatory growth effects of butyrate with increased papillae area and VFA absorption rate in rumen-fistulated goats given sodium butyrate compared with control animals. In our case, due to absence of an overall treatment effect, butyrate concentrations and ketogenic gene expression were not measured.

Effects of Age. Mass of the rumen wall of cranial ventral biopsy samples was not different between 4 compared with 8 wk of age. Mass of the rumen epithelium of cranial ventral biopsy samples was greater at 8 compared with 4 wk of age $(P<0.001$; Table 3$)$ and can likely be attributed to increased starter intake (Stobo et al., 1966; Beharka et al., 1998; Khan et al., 2008). Sander et al. (1959) suggested an increase in metabolic activity of rumen tissue from absorbed VFA leads to increased weight of the rumen mucosa layer, which suggests that calves in this study at wk 8 had much better capacity for metabolism of VFA compared with wk-4 calves due to more rumen epithelial tissue being present. Ruminal ketogenesis can be considered part of VFA metabolism and is a hallmark of mature ruminants. The capacity of rumen tissue to support ketogenesis is apparently age-dependent and is not affected by solid feed intake or intraruminal VFA con- 
centration, which are both recognized stimulators of morphological development of the rumen (Lane et al., 2000, 2002; Naeem et al., 2012). In milk-fed-only lambs, it was noted that BHBA production is minimal before $42 \mathrm{~d}$ of age (Lane et al., 2000). We suspect, but did not verify that the wk- 8 calves in our study had more ruminal ketogenesis occurring at the time of examination than the 4 -wk-old calves.

In our study, rumen papillae measurements were only obtained in wk- 8 calves due to the small size of papillae from in 4-wk-old calves. Beharka et al. (1998) noted similar papillae lengths $(4.6 \pm 0.3 \mathrm{~mm})$ in the cranial regions of the rumen in 11-wk-old calves fed either a ground diet or control diet. Castells et al. (2013) measured papillae in 11-wk-old Holstein starter fed calves and found similar papillae length $(4.12 \pm 0.32 \mathrm{~mm})$ to calves in our study, but smaller papillae width $(0.29 \pm$ $0.05 \mathrm{~mm})$ and smaller papillae surface area $\left(1.4 \mathrm{~mm}^{2}\right)$.

Our final assessment of rumen composition centered on thickness of the submucosa and tunica muscularis layers of the rumen tissue. The submucosal tissue layer is comprised of many extracellular components as well as vasculature for transporting nutrients to and from the rumen (Baldwin, 1998). Eight-week-old calves had a thicker submucosa $(0.58 \pm 0.06 \mathrm{~mm})$ compared with 4-wk-old calves $(0.25 \pm 0.06 \mathrm{~mm} ; P<0.001$, Table $3)$. The tunica muscularis surrounds the rumen and is composed of 2 opposing sheets of smooth muscle. It is responsible for contraction of the rumen and assists with peristalsis. In our study, thickness of the tunica muscularis was greater in 8- compared with 4-wk-old calves $(P=0.019$; Table 3$)$. Heinrichs (2005) noted that increase in musculature of the rumen is promoted by physical stimulation in the rumen, which can be from any large object but results mainly from dietary forages and, to a lesser extent, concentrate feeds. Forage was not fed in our study, but the greater starter intake of 8- compared with the 4-wk-old calves likely accounted for the observed increased in muscle thickness. As expected, both submucosal and tunica muscularis thickness were positively correlated with empty rumen weight $(\mathrm{r}=0.632, P=0.024$ and $\mathrm{r}=0.413, P$ $=0.002$, respectively).

\section{Calf Health and Medical Treatment Costs}

Initial serum IgG concentrations of calves were used to assess failure of passive transfer (FPT) of immunity and were used as a blocking factor in our study. Weaver et al. (2000) stated that successful passive transfer of immunity occurs when serum IgG concentration is $>10$ $\mathrm{mg} / \mathrm{mL}$; values under $10 \mathrm{mg} / \mathrm{mL}$ coincide with $\mathrm{FPT}$. No individual calves used in our study had FPT and the overall mean was $19.79 \pm 0.79 \mathrm{mg} / \mathrm{mL}$ (data not shown). Monitoring FPT by use of serum IgG levels does not guarantee disease-free calf rearing, but rather indicates an immune system better prepared to fight disease (Weaver et al., 2000).

Fecal and Respiratory Scores. The 2007 NAHMS survey revealed that diarrhea and respiratory problems were the first $(56.5 \%)$ and second $(22.5 \%)$ leading causes of mortality in preweaned heifers, respectively (USDA, 2010). These numbers changed in weaned heifers, which showed diarrhea and respiratory problems causing 12.6 and $46.5 \%$ of mortality, respectively (USDA, 2010). Alleviating incidence of diarrhea in calves would not only promote calf health, but would possibly allow for better calf growth due to energy not being shifted to the calf's immune system. In our study, inclusion of a fermentation extract of $A$. oryzae did not affect fecal or respiratory score throughout the entire duration (Table 4 ), but linear and quadratic effects of week were noted for both $(P<0.001$ and $P<0.05$, respectively). Both fecal and respiratory scores decrease over time, but it appears at certain weeks throughout the study the average scores increased slightly (wk 5 and 6 for fecal scores and wk 4, 6, and 7 for respiratory scores).

Medical Treatment Costs. Table 4 shows the percentage of calves treated for diarrhea and respiratory ailments and the total cost for these treatments per week. Treating diarrhea for calves consisted of administering Prevail to help with reducing fever, oral administration of electrolytes, and oral administration of Sustain III boluses if necessary. Treating respiratory ailments consisted of administering Prevail to help reduce fever as well as the treatments of either Draxxin, Excenel, or Nuflor. Percentage of calves treated for diarrhea did not differ by the 2 -way interaction of treatment $\times$ week or main effect of treatment, but percentage of calves treated differed throughout the duration of the study $(P<0.001)$ following a linear pattern of decreasing percentage overall as well as a quadratic pattern of slightly increasing in wk 5 before decreasing again. The cost of treating diarrhea per calf throughout the study did not differ by 2 -way interaction of treatment $\times$ week or treatment, but followed a linear and quadratic pattern for week $(P<0.0001)$ with an overall linear decrease in cost except for an increase in wk 5 . This decrease in cost of treating diarrhea is indicated by a decline for all calves from wk 1 (\$284.13) to $2(\$ 227.15)$ to 3 $(\$ 109.34)$, which for the most part (except for wk 5) continued to decrease through wk 8 (\$40.81). Percentage of calves treated for respiratory ailments was not affected by the 2 -way interaction of treatment $\times$ week, but was lower for AMF calves compared with CON calves $(P=0.040)$ and decreased linearly throughout the duration of the study $(P<0.001)$. The cost of treating respiratory ailments per calf was not differ- 
FEEDING ASPERGILLUS ORYZAE EXTRACT TO CALVES

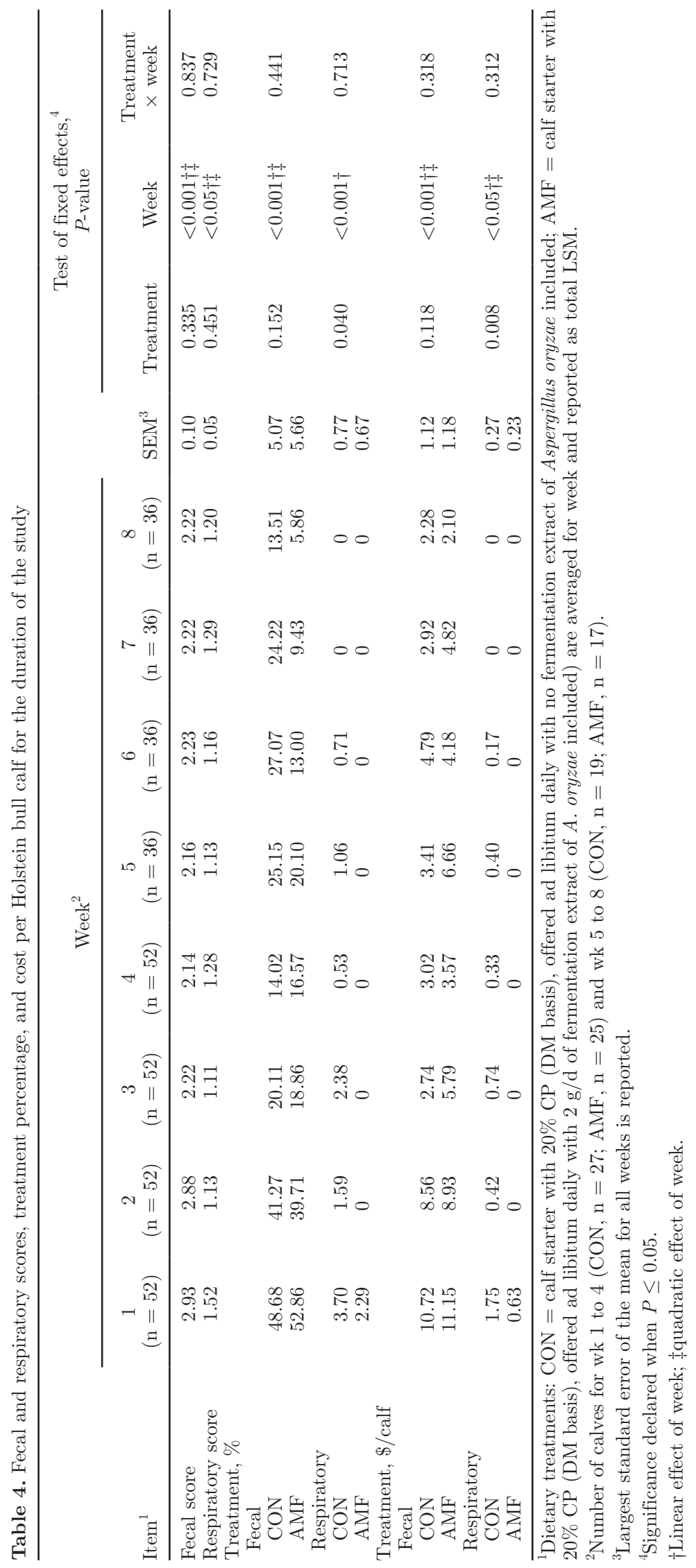


ent for the 2-way interaction of treatment $\times$ week, but was lower for AMF calves compared with $\mathrm{CON}$ calves $(P=0.008)$. The total cost of treating respiratory ailments in CON calves was $\$ 47.25$ in wk 1 compared with AMF calves, which was only $\$ 15.75$ (Table 4 ). The cost per calf for treating respiratory ailments differed $(P<0.05)$ in a linear and quadratic fashion throughout the duration of the study with AMF calves having no treatments for respiratory ailments following the first week, which most likely explains the difference in cost between treatments as well as a slight increase in cost for CON calves in wk 3. Total respiratory treatment costs after wk 1 were for CON calves only, which decreased at wk $2(\$ 11.34)$, increased at wk $3(\$ 19.98)$, and then decreased in wk $4(\$ 8.91), 5(\$ 7.60)$, and 6 (\$3.23) until no treatments were given in wk 7 and 8. Average total treatment cost throughout the study did not differ between treatment $(P=0.280$; data not shown). It is worth noting that the high cost of treatments was most likely due to extensive use of electrolytes and particularly Draxxin (primarily due to its low slaughter withhold time), which was expensive. Average total treatment cost decreased as the study went on $(P<0.001$; data not shown). Calves used for our study came from 13 different farms in the surrounding area and, despite their generally good immune status (i.e., acceptable serum IgG levels) upon arrival, pathogens may have been introduced between calves that caused respiratory or gastrointestinal infections.

The cost of administering a fermentation extract of A. oryzae to a calf for the entire 8-wk duration of our study at $2 \mathrm{~g} / \mathrm{d}$ cost $\$ 1.46$. This was not factored into the costs mentioned previously. It was thought that administering the fermentation extract of $A$. oryzae could possibly improve calf health, and although a decrease in treatments for respiratory ailments in AMF calves was noted, no clear explanation was available. Had we administered the fermentation extract of $A$. oryzae to calves that were immunocompromised (i.e., FPT from not administering colostrum), we may have observed a benefit of dietary inclusion.

\section{CONCLUSIONS}

In our 8-wk experiment with 52 purchased immunocompetent bull calves, we observed no differences between CON and AMF calves in terms of growth, feed intake, gross and histological rumen measurements, and most health measurements. Despite total medical costs not differing by treatment, a lower percentage of AMF calves were treated for respiratory ailments and respiratory treatment cost was lower for AMF compared with CON. All calves, regardless of treatment, grew at an acceptable rate showing no inhibitory or stimulatory effects of the A. oryzae fermentation extract on growth. Several factors may have contributed to an overall lack of observed treatment effect in this study. These include the use of a low-forage (compared with concentrate) diet, immunocompetent calves, and the selected product dose and routes of delivery. Dietary inclusion $(2 \mathrm{~g} / \mathrm{d})$ of an extract of $A$. oryzae did not affect calf growth, intake, or health measurements.

\section{ACKNOWLEDGMENTS}

The authors thank Biozyme Inc. (St. Joseph, MO) for providing the liquid and dry Amaferm product as well as financial support that made this project possible. In addition, we thank the Ohio Dairy Research Fund (Columbus) for agreeing to help fund the project as well. Additionally, we thank our undergraduate interns at OARDC: E. M. Dudash, R. M. Townsley, Y. Roman-Garcia, and A. R. Gibson for their help with the animal portion of this study.

\section{REFERENCES}

Anderson, K. L., T. G. Nagaraja, and J. L. Morrill. 1987a. Ruminal metabolic development in calves weaned conventionally or early. J. Dairy Sci. 70:1000-1005.

Anderson, K. L., T. G. Nagaraja, J. L. Morrill, T. B. Avery, S. J. Galitzer, and J. E. Boyer. 1987b. Ruminal microbial development in conventionally or early-weaned calves. J. Anim. Sci. 64:12151226.

Baldwin, R. L., VI. 1998. Use of isolated ruminal epithelial cells in the study of rumen metabolism. J. Nutr. 128:293S-296S.

Beharka, A. A., T. G. Nagaraja, and J. L. Morrill. 1991. Performance and ruminal function development of young calves fed diets with Aspergillus oryzae fermentation extract. J. Dairy Sci. 74:43264336.

Beharka, A. A., T. G. Nagaraja, J. L. Morrill, G. A. Kennedy, and R. D. Klemm. 1998. Effects of form of the diet on anatomical, microbial, and fermentative development of the rumen of neonatal calves. J. Dairy Sci. 81:1946-1955.

Bowen Yoho, W. S., V. A. Swank, M. L. Eastridge, K. M. O'Diam, and K. M. Daniels. 2013. Jersey calf performance in response to highprotein, high-fat liquid feeds with varied fatty acid profiles: Intake and performance. J. Dairy Sci. 96:2494-2506.

Castells, L., A. Bach, A. Aris, and M. Terré. 2013. Effects of forage provision to young calves on rumen fermentation and development of the gastrointestinal tract. J. Dairy Sci. 96:5226-5236.

Coleman, D. A., B. R. Moss, and T. A. McCaskey. 1996. Supplemental shade for dairy calves reared in commercial calf hutches in a southern climate. J. Dairy Sci. 79:2038-2043.

Counotte, G. H. M., R. A. Prins, R. H. A. M. Janssen, and M. J. A. deBie. 1981. Role of Megasphaera elsdenii in the fermentation of DL- $\left[2{ }^{13} \mathrm{C}\right]$ lactate in the rumen of dairy cattle. Appl. Environ. Microbiol. 42:649-655.

Davis, C. L., and J. K. Drackley. 1998. The Development, Nutrition, and Management of the Young Calf. Iowa State University Press, Ames, IA.

Davis, M. S., T. L. Mader, S. M. Holt, and A. M. Parkhurst. 2003. Strategies to reduce feedlot cattle heat stress: Effects on tympanic temperature. J. Anim. Sci. 81:649-661.

Diaz, M. C., M. E. Van Amburgh, J. M. Smith, J. M. Kelsey, and E. L. Hutten. 2001. Composition of growth of Holstein calves fed milk replacer from birth to 105-kilogram body weight. J. Dairy Sci. 84:830-842. 
Gebremendhin, K. G., C. O. Cramer, and W. P. Porter. 1981. Predictions and measurements of heat production and food and water requirements of Holstein calves in different environments. Trans. ASAE 24:715-720.

Gorka, P., Z. M. Kowalski, P. Pietrzak, A. Kotunia, R. Kiljanczyk, J. Flaga, J. J. Holst, P. Guilloteau, and R. Zabielski. 2009. Effect of sodium butyrate supplementation in milk replacer and starter diet on rumen development in calves. J. Physiol. Pharmacol. 60(Suppl. 3):47-53.

Heinrichs, J. 2005. Rumen development in the dairy calf. Adv. Dairy Technol. 17:179-187.

Hill, S. R., K. F. Knowlton, K. M. Daniels, R. E. James, R. E. Pearson, A. V. Capuco, and R. M. Akers. 2008. Effects of milk replacer composition on growth, body composition, and nutrient excretion in preweaned Holstein heifers. J. Dairy Sci. 91:3145-3155.

Khan, M. A., H. J. Lee, W. S. Lee, H. S. Kim, S. B. Kim, S. B. Park, K. S. Back, J. K. Ha, and Y. J. Choi. 2008. Starch source evaluation in calf starter II: Ruminal parameters, rumen development, nutrient digestibilities, and nitrogen utilization in Holstein calves. J. Dairy Sci. 91:1140-1149.

Lane, M. A., R. L. Baldwin VI, and B. W. Jesse. 2000. Sheep rumen metabolic development in response to different dietary treatments. J. Anim. Sci. 78:1990-1996.

Lane, M. A., R. L. Baldwin VI, and B. W. Jesse. 2002. Developmental changes in ketogenic enzyme gene expression during sheep rumen development. J. Anim. Sci. 80:1538-1544.

Li, R. W., E. E. Connor, C. Li, R. L. Baldwin VI, and M. E. Sparks. 2012. Characterization of the rumen microbiota of pre-ruminant calves using metagenomic tools. Environ. Microbiol. 14:129-139.

Malhi, M., H. Gui, L. Yao, J. R. Aschenbach, G. Gaebel, and Z. Shen. 2013. Increased papillae growth and enhanced short-chain fatty acid absorption in the rumen of goats are associated with transient increases in cyclin D1 expression after ruminal butyrate infusion. J. Dairy Sci. 96:7603-7616.

Naeem, A., J. K. Drackley, J. Stamey, and J. J. Loor. 2012. Role of metabolic and cellular proliferation genes in ruminal development in response to enhanced plane of nutrition in neonatal Holstein calves. J. Dairy Sci. 95:1807-1820.

Nagaraja, T. G., and E. C. Titgemeyer. 2007. Ruminal acidosis in beef cattle: The current microbiological and nutritional outlook. J. Dairy Sci. 90(E-Suppl.):E17-E38.

NRC. 2001. Nutrient Requirements of Dairy Cattle. 7th rev. ed. Natl. Acad. Press, Washington, DC.

O'Brien, M. D., R. P. Rhoads, S. R. Sanders, G. C. Duff, and L. H. Baumgard. 2010. Metabolic adaptations to heat stress in growing cattle. Domest. Anim. Endocrinol. 38:86-94.

Orskov, E. R. 1972. Reflex closure of the oesophageal groove and its potential application in ruminant nutrition. S. Afr. J. Anim. Sci. 2:169-172.

Puch, H. C., K. M. O'Diam, and K. M. Daniels. 2012. Techniques for sampling and measuring total two-dimensional surface area of rumen papillae. J. Dairy Sci. 95(Suppl. 2):615. (Abstr.)

Sakata, T., and H. Tamate. 1978. Rumen epithelial cell proliferation accelerated by rapid increase in intraruminal butyrate. J. Dairy Sci. 61:1109-1113.
Sander, E. G., R. G. Warner, H. N. Harrison, and J. K. Loosli. 1959. The stimulatory effect of sodium butyrate and sodium propionate on the development of rumen mucosa in the young calf. J. Dairy Sci. 42:1600-1605.

Schmidt, J. A., S. Albright, G. M. Calza, and R. E. Calza. 2004. Characterization of Aspergillus oryzae fermentation extract effects on the rumen fungus Neocallimastix frontalis, EB 188. Part 2. Carbon source utilization and effects on zoospore production. Appl. Microbiol. Biotechnol. 63:431-437.

Scott, S. L., R. J. Christopherson, J. R. Thompson, and V. E. Baracos. 1993. The effect of a cold environment on protein and energy metabolism in calves. Br. J. Nutr. 69:127-139.

Shen, Z., H. M. Seyfert, B. Loehrke, F. Schneider, R. Zitnan, A. Chudy, S. Kuhla, H. M. Hammon, J. W. Blum, H. Martens, H. Hagemeister, and J. Voigt. 2004. An energy-rich diet causes rumen papillae proliferation associated with more IGF type 1 receptors and increased plasma IGF-1 concentrations in young goats. J. Nutr. 134:11-17.

Stobo, I. J., J. H. Roy, and H. J. Gaston. 1966. Rumen development in the calf I: The effect of diets containing different proportions of concentrates to hay on rumen development. Br. J. Nutr. 20:171188.

Toullec, R., and P. Guilloteau. 1989. Research into the digestive physiology of the milk-fed calf. Pages $37-55$ in Nutrition and Digestive Physiology in Monogastric Farm Animals. J. Van Weerdon and J. Huisman, ed. Pudoc Scientific Publishers, Wageningen, the Netherlands.

Uchida, H., S. Arakida, T. Sakamoto, and H. Kawasaki. 2006. Expression of Aspergillus oryzae phytase gene in Aspergillus oryzae RIB40 niaD-. J. Biosci. Bioeng. 102:564-567.

USDA. 2010. Dairy 2007, Heifer Calf Health and Management Practices on US Dairy Operations, 2007. USDA:APHIS:VS, CEAH, Fort Collins, CO.

Von Engelhardt, W., and J. R. Hales. 1977. Partition of capillary blood flow in rumen, reticulum, and omasum of sheep. Am. J. Physiol. 232:E53-56.

Waldrip, H. M., and S. A. Martin. 1993. Effects of an Aspergillus oryzae fermentation extract and other factors on lactate utilization by the ruminal bacterium Megasphaera elsdenii. J. Anim. Sci. $71: 2770-2776$.

Weaver, D. M., J. W. Tyler, D. C. VanMetre, D. E. Hostetler, and G. M. Barrington. 2000. Passive transfer of colostral immunoglobulins in calves. J. Vet. Intern. Med. 14:569-577.

Zerby, H. N., J. L. Bard, S. C. Loerch, P. S. Kuber, A. E. Radunz, and F. L. Fluharty. 2011. Effects of diet and Aspergillus oryzae extract or Saccharomyces cervisiae on growth and carcass characteristics of lambs and steers fed to meet requirements of natural markets. J. Anim. Sci. 89:2257-2264.

Zimbelman, R. B., R. P. Rhoads, M. L. Rhoads, G. C. Duff, L. H. Baumgard, and R. J. Collier. 2009. A re-evaluation of the impact of temperature-humidity index (THI) and black globe humidity index (BGHI) on milk production in high producing dairy cows. Pages 158-168 in Proc. Southwest Nutr. Manage. Conf., Tempe, AZ. University of Arizona, Tucson, AZ. 